\title{
О ПОВЫШЕНИИ КОНКУРЕНТОСПОСОБНОСТИ СОХРАНИВШИХСЯ ПРОИЗВОДСТВ ОБРАБАТЫВАЮЩЕЙ ПРОМЫШЛЕННОСТИ
}

\author{
Корнев А.К.
}

Исследуются способы дотирования производств обрабатывающей промышленности. В условиях открытой рыночной экономики предлагается возврат к перераспределению природной ренты, как максимальному дотированию. Для этого необходимо преобразование существующиих производств обрабатывающей промышленности в вертикально интегрированные межотраслевые корпорации.

DOI: $10.20537 /$ mce2019econ01

Развитие отечественной обрабатывающей промышленности является сложной задачей, решение которой в каждый период времени требует применения новых производственных форм и подтверждения их возможностей. Это связано с тем, что обрабатывающие производства в нашей стране вынуждены осуществлять, как известно, дополнительные капитальные и текущие затраты. Они функционально связанны с конкретным показателем глубины промерзания грунта в регионе и необходимы для компенсации воздействия холодного климата. Эти дополнительные затраты отсутствуют в развитых странах, расположенных преимущественно в условиях субтропического климата, рядом с теплым течением. Дополнительные затраты определяют удорожание производимой отечественной продукции обрабатывающей промышленности, и делают ее неконкурентоспособной в ценовом отношении по сравнению с ее зарубежными аналогами.

Вместе с тем отечественная практика советского периода показывает, что на основе выделения этим обрабатывающим производствам дотаций, превышающих объемы удорожания продукции, может быть осуществлено ее удешевление до необходимого уровня и тем самым подтверждена ее ценовая конкурентоспособность. Советская практика свидетельствует также о том, что, несмотря на очень значительные величины дотаций, они могут быть успешно распространены на все обра- 
батывающие производства, существующие в экономике. Указанный подход является общим решением проблемы ценовой конкурентоспособности отечественной продукции обрабатывающей промышленности. Что касается качественной стороны изделия, то часто необходимо, чтобы оно входило в какой-то класс, соответствовало каким-то типоразмерам, показателям массы, мощности двигателя. Именно достижение среднего ценового уровня класса изделия и является целью дотирования выпуска продукции.

\section{Способы обеспечения ценовой конкурентоспособности про-} дукции обрабатывающей промышленности. Как известно, может быть несколько постоянных источников дотаций для обеспечения ценовой конкурентоспособности отечественной продукции обрабатывающей промышленности. Каждый из них предполагает создание определенного механизма выделения, сбора, передачи и приема финансовых средств. Совместно постоянный источник дотаций и указанный механизм образуют способ дотирования продукции обрабатывающей промышленности. Соответственно количество способов дотирования совпадает с количеством постоянных источников дотаций.

Советская практика, как известно, конструктивно и провидчески наилучшим образом определилась с выбором постоянных источников дотаций производственным предприятиям и объединениям обрабатывающей промышленности, а именно: на основе перераспределения природной ренты. В процессе выбора были рассмотрены все другие постоянные источники дотаций, охарактеризованы как неприемлемые и поэтому не были включены в практическую сферу. Этими постоянными источниками дотаций являются, во-первых, вычет финансовых ресурсов из фонда заработной платы занятых на производстве (возможно снижение уровня жизни населения и рост социальной напряженности в обществе). Вовторых, вычет из доходов собственника производства (возможно разорение собственника обрабатывающего производства и разрушение производственных процессов). В-третьих, вычеты из созданного перераспределительного государственного фонда, формируемого преимущественно из налоговых поступлений производственных предприятий и объединений (с целью выделения дотаций производствам обрабатывающей промышленности). В отношении его не было уверенности в том, что в условиях необходимого развития обрабатывающей промышленности финансовых ресурсов перераспределительного фонда будет достаточно для поддержки предприятий и объединений. Кроме того, не были решены многие во- 
просы его формирования, и он был признан крайне громоздким в качестве экономического инструмента, к тому же не гарантирующим необходимые определенные результаты его применения.

\section{Способ дотирования продукции обрабатывающей промыш-} ленности в советский период. Как известно, в этот период, характеризуемый успешной индустриализацией отечественной экономики, конкурентоспособность продукции обрабатывающей промышленности обеспечивалась системным образом на основе дотаций, использовавших разнообразие и большую стоимость природных богатств нашей страны. В том числе, прежде всего, природную ренту, получаемую в результате разработки и транспортировки природных ресурсов. Этот новый подход с использованием природной ренты оказался осуществимым благодаря исследованиям и разработкам, проведенным в указанный период времени в рамках закрытой экономики. В отечественной экономике дотации осуществлялись в результате перераспределения природной ренты, возникающей в добывающей промышленности, в пользу производств обрабатывающей промышленности с применением фиксации низкого уровня цен на продукцию добывающей период времени в рамках закрытой экономики. Это перераспределение природной ренты происходило без передачи финансовых средств.

В то же время, необходимо отметить, что часть прибылей обрабатывающей промышленности, получаемых от продажи ее конечной продукции, как на внутреннем рынке, так и за рубежом, взаимообразно в необходимом количестве направлялась в добывающую промышленность с целью обновления ее достаточно капиталоемкого производственного аппарата. При этом высокий уровень прибылей обрабатывающей промышленности обеспечивался значительными объемами серийного производства этой продукции, которые способствовали снижению уровня затрат на ее выпуск. Одновременно минимизировались закупки аналогичной импортной продукции, способные уменьшить спрос на отечественную продукцию. Рассматриваемый способ обеспечения конкурентоспособности продукции обрабатывающей промышленности был уникальным и разработан специально для обеспеченной ресурсами, закрытой, огосударствленной, плановой экономики, характеризуемой в целом как модель, ориентированная на то, чтобы догонять в своем развитии ведущие страны мира. Экономика того периода отличалась также централизованно устанавливаемыми структурными пропорциями, ценами и отраслевым планированием объемов производства продукции. 
Важную роль в ней играли перераспределительные процессы, использующие гарантии, данные государством и им устанавливаемые цены. Однако, безусловно, главным в рассматриваемом способе обеспечения дотациями производственных предприятий и объединений было создание и поддержание закрытой отечественной экономики.

Создание государственного перераспределительного фонда. Как известно, в постсоветский период в результате проведения радикальных реформ, в том числе приватизации предприятий, либерализации цен и создания открытой экономики, увеличился экспорт продукции добывающей промышленности по высоким ценам международного рынка, включающим полную стоимость природной ренты [1]. Экспорт сырьевых ресурсов привел к сокращению объемов потребления этой продукции в российской экономике и росту внутренних цен на нее. В итоге роста цен природная рента остается в распоряжении производств добывающей промышленности [2]. Вместе с тем производственные предприятия и объединения обрабатывающей промышленности теряют дотации, их продукция становится дороже, она оказывается неконкурентоспособной в ценовом отношении, объемы ее сбыта уменьшаются, доходы ее производителей сокращаются. Производственный аппарат предприятий и объединений изнашивается и устаревает, а его обновление и модернизация задерживаются из-за недостатка финансовых средств на их осуществление. В конечном итоге производители продукции обрабатывающей промышленности становятся банкротами и ликвидируются, если им не оказывается своевременная государственная поддержка. Ликвидация отдельных предприятий и объединений способна привести к утрате целых производственно-технологических цепочек. Эти утраты определяют деиндустриализацию экономики.

Деиндустриализация экономики оказывает колоссальное влияние, определяющее ухудшение общих показателей развития народного хозяйства. Согласно расчетам В. Симчеры, директора НИИ статистики Росстата в 2001-2010 гг., автора монографии «Развитие экономики России за 100 лет, 1900-2000». В настоящее время валовой внутренний продукт нашей страны составляет только 40\% его уровня в РСФСР в 1990 г. [3]. Утрата $60 \%$ отечественной экономики того периода в значительной мере связана с вывозом капиталов, деиндустриализацией, особенно колоссального по размерам инвестиционного машиностроения, и ее последствиями для оставшейся части народного хозяйства. В настоящее время происходит также очень значительное уменьшение оценок запасов сохранивших- 
Корнев А.К. О повышении конкурентоспособности сохранивиихся..., стр. 9-23

Kornev A.K. Rising the competitiveness of the remaining manufacturing..., pp. 9-23

ся ресурсов, а также доли национальных производств [4]. При этом бенефициарами проводимой экономической политики оказываются не население и не обрабатывающая промышленность [5].

Сохранившиеся предприятия и объединения обрабатывающей промышленности получают регулярную государственную поддержку в различных формах. Необходимость сохранить от банкротства и ликвидации производственные предприятия и объединения обрабатывающей промышленности определила образование государственного перераспределительного фонда с целью их финансовой поддержки. Создание этого фонда является необходимым и вынужденным обстоятельством, возможно, его возникновение было осуществлено с некоторым запозданием. Государственный перераспределительный фонд формируется и пополняется различными способами, однако, прежде всего, из налогов, значительно увеличивая тем самым налоговое бремя на производителей продукции.

Фонд существует в разных формах, например, некоторыми частями на разных уровнях властной вертикали: федеральном, региональном, областном. Он способен обеспечивать финансовую поддержку в соответствии с определенными социальными (например, развитие единственного крупного производства в городе) и экономическими программами. По решению государственных органов власти в обязанности фонда может включаться финансовая поддержка и других субъектов экономики (например, выплаты финансовых средств сетевым супермаркетам с целью компенсации роста цен на определенные виды продукции, признанные экспертами как общественно значимые). Услугами фонда могут быть также льготные кредиты, выдаваемые определенными банками.

Кроме того, финансовые выплаты могут быть целевыми, направленными, например, на обновление и модернизацию производственного аппарата конкретного производителя продукции обрабатывающей промышленности. Выделение дотаций может осуществляться также в виде гарантированной максимальной суммы финансовых средств, выделяемой с целью избежать банкротства производителя в течение определенного периода времени. Функцию поддержки производителя продукции может выполнять государственный заказ. В этом случае государственный заказ может предусматривать не только производство каких-то объемов определенной продукции, например, для финансово обеспе- 
ченного ведомства, но и предварительное обновление производственной базы, в том числе с использованием импортной техники.

Фонд нередко используется не по назначению, и в этом случае производители продукции обрабатывающей промышленности могут оказываться без финансовой господдержки. Тогда им остается надеяться только на себя и следующие по времени выплаты из фонда. Собственные возможности этих производителей продукции заключаются, прежде всего, в дотационных вычетах из фонда заработной платы занятых на этих производствах. Однако высокий уровень налогообложения предприятий и объединений обрабатывающей промышленности определяет низкий уровень заработной платы занятых на них. Поэтому дотационный вычет из фонда заработной платы не может осуществляться длительный период времени и быть в достаточной мере успешным (в начале постсоветского периода, когда заработная плата могла многие месяцы не выплачиваться, значение дотационного вычета из фонда заработной платы было значительно больше).

В этой ситуации могут производиться и дотационные вычеты из доходов собственника производства. Они, с одной стороны, способны значительно продлить период существования производственных предприятий и объединений обрабатывающей промышленности без государственной поддержки из перераспределительного фонда, а с другой стороны, собственники этих производств оказываются в уязвимом положении, лишаются возможностей быстрой адекватной реакции, включающей дополнительные инвестиции, усовершенствования производственного процесса, необходимые приобретения. В течение длительного периода времени указанных дотаций из фонда заработной платы и доходов собственника может оказаться недостаточно для поддержания функционирования производства, а тогда могут произойти и банкротство производителя, и ликвидация его предприятия.

\section{Оптимизация расходов перераспределительного государст-} венного фонда как неизбежное явление современной экономики. Нередко выплаты из перераспределительного фонда осуществляются с задержкой по отношению к производственному процессу сохранившихся предприятий и объединений. Из-за этой задержки цены на производимую продукцию в течение некоторого периода времени невозможно снизить, они оказываются завышенными по сравнению с ценами на аналогичную зарубежную продукцию. Поэтому объемы реализации продукции уменьшаются, доходы сокращаются, расходы производителя 
Корнев А.К. О повышении конкурентоспособности сохранивиихся..., стр. 9-23

Kornev A.K. Rising the competitiveness of the remaining manufacturing..., pp. 9-23

продукции поддерживаются за счет дотаций, а обновление и модернизация производственного аппарата могут задерживаться в связи с недостатком финансовых средств. Таким образом, финансовое положение сохранившихся производителей продукции обрабатывающей промышленности может оказываться неустойчивым даже в условиях получения ими финансовой поддержки.

Указанная финансовая неустойчивость производств связана, безусловно, с выбором способа их финансовой поддержки. В процессе реформирования экономики были отвергнуты и далее оказались невозможными дотации на основе перераспределения природной ренты, буквально сопровождавшие производственный процесс обрабатывающей промышленности. В то же время средства перераспределительного фонда крайне ограничены, этих средств было в несколько раз меньше, чем необходимо в качестве дотаций для всей обрабатывающей промышленности, существовавшей в начале постсоветского периода.

В результате банкротств и ликвидаций многих производств обрабатывающей промышленности в постсоветский период потребность в дотациях снизилась. Однако, по-прежнему, потребности в дотациях для сохранившихся производств значительно превышают возможности их поддержки на основе использования перераспределительного фонда. Дело в том, что в процессе функционирования перераспределительного фонда происходят расширение его функций, увеличение числа решаемых задач и объектов его деятельности, уменьшается та часть фонда, которая предназначена для поддержки производственных предприятий и объединений обрабатывающей промышленности. В результате осуществляются дополнительные их банкротства и ликвидации.

Сокращение части перераспределительного фонда, предназначенной для поддержки производств (с целью расширения функций фонда и решения других задач) происходит с использованием оптимизации расходов перераспределительного фонда, которая ориентирована на сокращение выплат из него выделенным производствам обрабатывающей промышленности. То есть на основе искусственного уменьшения потребности в финансовой поддержке путем выборочного отказа в ней. При этом предполагается сохранение основных конечных итогов производственной деятельности обрабатывающей промышленности в краткосрочный период. Оптимизация расходов оказывается возможной и необходимой по той причине, что как потенциальная, так и фактическая финансовая поддержка производителей обрабатывающей промышлен- 
ности из перераспределительного фонда значительно меньше, чем потребности в ней. Оптимизация расходов перераспределительного фонда означает отказ от максимально возможного развития обрабатывающей промышленности, поиск некоего локального оптимума, который является условным и может изменяться в зависимости от объемов сохранившихся производств обрабатывающей промышленности. Этот временный оптимум свидетельствует о соотношении объемов производства продукции различных групп обрабатывающей промышленности, в том числе закупаемой по импорту. При этом объемы производства отечественной продукции постоянно уменьшаются, объемы импортной продукции в целом увеличиваются в результате роста не столько разнообразия, сколько отдельных позиций продукции. (Необходимо отметить, что применение природной ренты в качестве дотаций позволяет обеспечить и поддержать развитие обрабатывающей промышленности, максимизировать объемы и разнообразие ее продукции, осуществить стратегию опережающего и приоритетного развития обрабатывающей промышленности, и в этих условиях в принципе не может быть оптимизации дотаций, поскольку они имеются в необходимом объеме.)

Оптимизация расходов перераспределительного фонда осуществляется, прежде всего, путем выявления в производственнотехнологических цепочках одного или нескольких производителей продукции обрабатывающей промышленности, которые регулярно получают финансовую государственную поддержку, а затем сравнения суммы господдержки этих производителей продукции со стоимостью закупки по импорту конечного изделия производственно-технологической цепочки. (Иногда осуществляется сравнение суммы господдержки производителей продукции в этой и следующей производственнотехнологических цепочках со стоимостью закупки по импорту конечной продукции второй цепочки). Часто оказывается, или, по крайней мере, утверждается с учетом каких-то дополнительных фактов, например, технического уровня, что более выгодно приобретать необходимую конечную продукцию по импорту и тем самым экономить финансовые средства господдержки. В этом случае происходит отказ в финансовой поддержке выявленным производителям продукции обрабатывающей промышленности, в течение определенного периода времени они оказываются банкротами и ликвидируются, как и одна или две производственно-технологические цепочки, в конечном итоге. А конечная продук- 
Корнев А.К. О повышении конкурентоспособности сохранивиихся..., стр. 9-23

Kornev A.K. Rising the competitiveness of the remaining manufacturing..., pp. 9-23

ция производственно-технологической цепочки закупается по импорту. Таким способом уменьшаются расходы перераспределительного фонда.

Необходимо отметить, что ликвидация значительного промышленного производственного аппарата в краткосрочный период может не увеличивать потребности в импорте продукции. А другие важные характеристики экономики при этом могут не учитываться, например, уменьшение валового внутреннего продукта, потенциала производства, коэффициента использования мощностей, занятости, увеличение потребностей экономики в среднесрочный период. Возможно даже в этих условиях накопление золотовалютных запасов, позволяющих при необходимости сравнительно быстро осуществить вложения в прорывные или новые технологии, значительно повышающие эффективность экономики. Однако сохранение производственного потенциала обрабатывающей промышленности. уже значительно уменьшенного, является крайне важной задачей в рамках общего развития страны.

Результаты оптимизации выплат из перераспределительного фонда с целью дотирования производства продукции обрабатывающей промышленности. Оптимизация расходов перераспределительного фонда осуществляется сравнительно длительный период времени. Ее результатом является дополнительная деиндустриализация экономики, ликвидация многих производственных предприятий и объединений обрабатывающей промышленности, производственно-технологических цепочек. В этих условиях подвержены оптимизации оказались, прежде всего, сохранившиеся ключевые производства (ядро) инвестиционного машиностроения, продукция которых должна была вместе с импортной техникой повышать технический уровень собственных ключевых производств в результате их модернизации и обновления производственного аппарата. А главной целью технического совершенствования ключевых производств является возможность обновления и модернизации отраслевых производств инвестиционного машиностроения. Таким образом, в начале инвестиционного процесса находятся мощности ключевых и отраслевых производств инвестиционного машиностроения.

В соответствии с общей логикой оптимизации сначала должно было происходить сравнение суммы финансовой поддержки производств в инвестиционных производственно-технологических цепочках, начинающихся ключевыми производствами и ими завершающихся, со стоимостью закупок импортной техники для ключевых производств. Однако низкое качество современных ключевых производств внесло корректи- 
ровку, состоящую в необходимости ориентироваться на альтернативные закупки импортной техники для реконструкции производственного аппарата ключевых производств. При этом объемы закупок машин и оборудования по импорту должны были бы быть очень значительными, чтобы возникла возможность инвестировать отраслевые производства инвестиционного машиностроения. Однако сравнение суммы дотаций ключевым производствам вместе с закупками для них импортной техники и затрат на закупки техники по импорту для отраслевых производств определило отказ от поддержки ключевых производств и предпочтение закупок техники по импорту для отраслевых производств инвестиционного машиностроения.

Таким образом, происходит ликвидация сохранившихся ключевых производств как представителей высшего уровня, осуществляется их перевод на низший уровень отраслевых производств инвестиционного машиностроения. В итоге изменяются и отраслевые производства инвестиционного машиностроения, они не могут длительный период времени оставаться прежними, если отсутствует инвестирование со стороны ключевых производств.

В связи с тем, что ключевые производства не были обновлены, они не в состоянии обновить и модернизировать отраслевые производства инвестиционного машиностроения. В этих обстоятельствах обновление и модернизация производственного аппарата отраслевых производств возможны на основе закупок импортной техники. Альтернативой им является закупка по импорту готовой техники, аналогичной той, которую должны производить отраслевые производства инвестиционного машиностроения. Оптимизация расходов перераспределительного фонда осуществляется на основе сравнения стоимости закупок импортной техники для обновления и модернизации производственного аппарата отраслевых производств инвестиционного машиностроения и стоимости закупок готовой импортной техники, аналогичной производимой этими отраслевыми производствами. Оптимизация расходов на поддержку производств отраслевого инвестиционного машиностроения привела к уменьшению объемов производства его продукции по многим позициям. Согласно нашим оценкам, из двадцати крупных видов производства продукции отраслевого инвестиционного машиностроения двенадцать позиций оказались в условиях оптимизации их финансовой государственной поддержки. Среди них необходимо выделить позиции, 
Корнев А.К. О повышении конкурентоспособности сохранивиихся..., стр. 9-23

Kornev A.K. Rising the competitiveness of the remaining manufacturing..., pp. 9-23

которые в перспективный период покажут малозначимый статистический результат.

Две группы продукции обрабатывающей промышленности, предназначенной для дальнейшего производственного использования и народного потребления - имеют почти одинаковый отраслевой состав. Так, продукцию народного потребления дополнительно производят предприятия и объединения гражданского машиностроения. Однако результаты функционирования этих производителей двух групп продукции значительно различаются. Производители продукции, предназначенной для дальнейшего производственного использования, в меньшей мере подверглись оптимизации в отношении их финансовой поддержки. Однако ряд из них лишились финансовой поддержки и в перспективный период обречены на значительное сокращение объемов производства продукции. Большая часть продукции этих отраслей промышленности приобретается по импорту.

В отношении всей группы товаров народного потребления была осуществлена оптимизация. С учетом того факта, что существует постоянный внутренний спрос со стороны населения на эти товары, отечественный рынок был полностью отдан в распоряжение иностранных производителей этих товаров. При этом отечественные бренды были сохранены и предоставлены иностранным производителям рассматриваемой продукции. В итоге с использованием отечественных брендов производятся 2-3 финишные операции (покраска, сборка), а остальная часть операций по изготовлению изделия осуществляется на территориях иностранных производителей. Ввоз в нашу страну этих изделий осуществляется в почти готовом виде, а оплата этих изделий производится в свободно конвертируемой валюте.

Технически сложные товары длительного пользования являются пятой группой продукции обрабатывающей промышленности. Эта группа продукции постоянно увеличивается в результате закупок по импорту технически сложных товаров. Отечественные товары в постсоветский период были почти полностью заменены на соответствующие товары зарубежного производства. Разнообразие и сложность этих товаров постоянно увеличиваются. Кроме того, эта группа продукции постоянно пополняется за счет усложнения товаров народного потребления. Оптимизация выплат из перераспределительного фонда коснулась всех производителей технически сложных товаров длительного пользования. В итоге произошли банкротства и ликвидации этих производителей. 


\section{О повышении конкурентоспособности сохранившихся произ-} водств обрабатывающей промышленности путем возврата к дотациям на основе перераспределения природной ренты. В перспективный период приоритетное ускоренное развитие обрабатывающей промышленности может оказаться возможным даже в условиях резкого сокращения определенной части сырьевого экспортного потенциала, которое может произойти через 20-30 лет [6]. Для обеспечения этого роста необходимо повысить конкурентоспособность сохранившихся производств обрабатывающей промышленности в настоящее время и осуществить широкомасштабную долгосрочную реиндустриализацию экономики [7]. В рамках этой реиндустриализации, безусловно, необходимо восстановить ключевые производства инвестиционного машиностроения. Затем должны быть созданы отраслевые производства инвестиционного машиностроения. Кроме того, должны быть созданы мощности, выпускающие продукцию производственного назначения, народного потребления, технически сложные товары длительного пользования.

Повышение в ближайший период времени конкурентоспособности сохранившихся производств обрабатывающей промышленности можно осуществить только на основе перераспределения природной ренты в пользу производств обрабатывающей промышленности в качестве их дотаций [8]. Для осуществления перераспределения природной ренты в открытой рыночной экономике, созданной в период реформ, необходимо использование ее новых субъектов. Сохранившиеся производственные предприятия и объединения обрабатывающей промышленности не могут быть полноценными субъектами открытой рыночной экономики, поскольку, по сути, являются останками плановой советской системы. Большая часть элементов этой системы (например, государственные комитеты по планированию, по науке и технике, по ценам, по труду, по материально-техническому снабжению, по стандартизации продукции и многие другие) была ликвидирована в начальный период радикальных реформ. Советская экономическая система не была использована для придания новых качеств и структурных элементов производственным предприятиям и объединениям, а также для трансформации их в современные самостоятельные производственные единицы. Обеспечить работоспособность новых структурных элементов, придать им новые качества могли информационные данные, накопленные в прежних советских структурах, а также их бывшие сотрудники, обладавшие опытом и знаниями. 
В настоящее время сохраняется необходимость трансформации сохранившихся предприятий и объединений в новые производственные структуры. Эти преобразования не могут быть осуществлены самими предприятиями и объединениями. Необходимую трансформацию могут осуществить специально созданные государственные структуры, например, государственный комитет по развитию обрабатывающей промышленности. Кроме того, потребуется дополнительная финансовая поддержка этих преобразований, осуществляемая банками при посредничестве нового государственного комитета.

Конкурентоспособность продукции сохранившихся производств обрабатывающей промышленности могут обеспечить новые закрытые корпорации, а именно: вертикально интегрированные межотраслевые ВИМК, сходные с зарубежными ТНК [9]. ВИМК должны включать длинную производственно-технологическую цепочку, которая начинается с предприятий добывающей промышленности, содержит производства инфраструктуры и завершается производствами обрабатывающей промышленности в качестве конечных. Внутри новых корпораций, как и действующих в настоящее время ТНК, должны использоваться нерыночные цены. Они обеспечат перераспределение природной ренты, возникающей в добывающих производствах, в пользу обрабатывающих производств в качестве их дотации и в результате формирование низкого уровня цен на конечную продукцию корпорации. В то же время прибыль от ее продажи должна использоваться, в том числе, для обновления производственного аппарата добывающих производств. Получению дополнительной прибыли от продажи продукции будет способствовать создание в составе корпорации научно-исследовательского центра, который обеспечит качественное совершенствование производимой продукции. Кроме того, необходимо создание в составе новой корпорации сервисного центра, способствующего рекламе, ремонту и реализации конечной продукции корпорации.

Вместе с тем должна измениться и конкурентная среда, окружающая новые корпорации. Сами ВИМК должны конкурировать с подобными им зарубежными производственными структурами, в том числе ТНК [10]. Именно очень большие производственные структуры способны качественно совершенствовать производимую продукцию, устанавливать соотношения между ее качеством и ценой на нее, определять тенденцию развития. Мелкий и средний бизнес в окружении ВИМК должен сопровождать производственно-технологическую цепочку кор- 
порации и претендовать на занятие места в ее составе в качестве более предпочтительного звена с точки зрения качества, эффективности, надежности, сокращения производственных операций и улучшения технологии. Кроме того, мелкий и средний бизнес должен претендовать на заключение с корпорацией договора о совместных разработках, проектах улучшения отдельных элементов производственно-технологической цепочки корпорации.

Создание ВИМК на основе сохранившихся предприятий обрабатывающей промышленности должны обеспечить органы государственной власти. В частности, государственный комитет по развитию обрабатывающей промышленности должен определить производственнотехнологические цепочки для каждой ВИМК. В случае отсутствия какихлибо определенных звеньев в этих цепочках госкомитет должен содействовать их восстановлению путем выделения кредитов, необходимых закупок импортной техники, использования реконструированных изделий. Отсутствующими звеньями могут быть конечные производства продукции, начальные добывающие мощности, параллельные дублирующие производства, позволяющие развести производственно-технологические цепочки и сделать их изолированными и самостоятельными.

Количество создаваемых ВИМК должно соответствовать количеству крупных отраслей обрабатывающей промышленности, собственность их должна быть государственно-корпоративной, а управление может производиться советом директоров корпорации. Для формирования, создания и развития ВИМК необходимо активно использовать такую форму, как государственно-частное партнерство между государственными органами власти и представителями собственников в составе новой корпорации. Оно должно осуществляться в отношении состава ВИМК, перечня производимой продукции, ее примерных объемов, направлений ее совершенствования и использования, финансовых обстоятельств корпорации и ее перспектив. 


\section{СПИСОК ЛИТЕРАТУРЫ}

1. Волконский В.А., Кузовкин А.И., Мудреиов А.Ф. Природная рента и методы ее оценки. Открытый семинар «Экономические проблемы энергетического комплекса» от 20 апреля 2004 года. ИНП РАН. Москва. 2004.

2. Корнев А.К., Максимиова С.И., Трещина С.В. Рост цен на продукцию добывающей промышленности в постсоветский период и деиндустриализация экономики // Проблемы прогнозирования. 2016. №5 (158). с.70-85.

3. Симчера В.Ф. Выборы - 2018: до и после. Выступление на заседании «Круглого стола в Изборском клубе» // Завтра. 2018. № 10 (1266).

4. Симчера В.Ф. Россия обесцененная. //Аргументы недели. 2019. №14 (658).

5. Глазьев С.Ю. О бенефициарах проводимой экономической политики // Apгументы недели. 2018. №35(628).

6. Фальиман В.К. О структуре, динамике и использовании активной части национального богатства // Проблемы прогнозирования. 2018. №5 (170). с.13-23.

7. Корнев А.К. Возможности роста отечественной экономики на основе ее реиндустриализации // Экономист. 2018. №7. с.3-16.

8. Корнев А.К. Производственный потенциал России: повышение конкурентоспособности обрабатывающей промышленности // Проблемы прогнозирования. 2014. №5(146). с.53-69.

9. Корнев А.К., Максимиова С.И., Трещина С.В. Вертикально интегрированные межотраслевые корпорации как форма перехода от деиндустриализации к реиндустриализации отечественной рыночной экономики // Проблемы прогнозирования. 2017. №5. с.50-58.

10. Корнев А.К., Максимщова С.И., Трещина С.В. Опыт мирового индустриального развития и реиндустриализация отечественной экономики // Проблемы прогнозирования. 2015.№ 5. с.63-78.

\section{RISING THE COMPETITIVENESS OF THE REMAINING MANUFACTURING COMPANIES}

Kornev A.K.

The ways to subsidize the production of manufacturing industry were analyzed. The author proposes the return to redistribution of natural rents as maximum subsidies in the market economy conditions. This requires transforming existing manufactures into vertically integrated cross-industry corporations. 